\title{
It Matters How Old You Feel: Antecedents and Performance Consequences of Average Relative Subjective Age in Organizations
}

\author{
Florian Kunze \\ University of Konstanz
}

\author{
Anneloes M. L. Raes \\ IESE Business School
}

\author{
Heike Bruch \\ University of St. Gallen
}

\begin{abstract}
This article extends the conceptual knowledge of average relative subjective age in organizations by exploring organizational-level antecedents and consequences of employees, on average, feeling younger than their chronological age. We draw from the theories of selection-optimization-compensation and socioemotional selectivity to build a theoretical framework for relative subjective age in organizations. We hypothesize that companies in which employees, on average, perceive themselves to be younger than they actually are have a higher average individual goal accomplishment and, in turn, experience higher company performance. We further hypothesize that employees' average experience of high work-related meaning relates to a lower subjective age in organizations. In addition, we assess the role of environmental dynamism and age-inclusive human resource management as moderators in this theoretical model. Through empirically testing this model in a multisource dataset, including 107 companies with 15,164 participating employees, we received support for the hypothesized relationships. Our results contribute to current debates in the scientific literature on age and have important practical implications in light of the demographic changes faced by many companies. This research indicates to both researchers and practitioners that it is not employees' chronological age but their subjective age, a factor that can be influenced, which drives organizational performance outcomes.
\end{abstract}

Keywords: subjective age, selection-optimization-compensation theory, socioemotional selectivity theory, age-inclusive human resource practices, company performance

\begin{abstract}
"Age is not how old you are, but how old you feel" (Garcia Marquez, 2007, p. 60). Subjective age is individuals' experience of being of a certain age and may be higher, lower, or equal to their chronological age (e.g., Barak, 2009; Barak \& Stern, 1986). Because feeling younger than chronological age has been related to increased health, vitality, and productivity (Montepare, 2009; Stephan, Chalabaev, Kotter-Grühn, \& Jaconelli, 2013), subjective age may be of interest in relation to employee behavior in organizations. Unfortunately, most research thus far on subjective age has been done among older adults (i.e., 65 years and older; Montepare, 2009), whereas organizational scholars have focused on chronological rather than subjective age (e.g., $\mathrm{Ng} \&$ Feldman,
\end{abstract}

Florian Kunze, Department of Politics and Public Administration, University of Konstanz; Anneloes M. L. Raes, IESE Business School, Barcelona, Spain; Heike Bruch, Institute for Leadership and Human Resource Management, University of St. Gallen.

A prior version of the article was presented at the 2014 Academy of Management Annual Meeting in Philadelphia. We would like to thank Lisa Finkelstein and Ulrich Leicht-Deobald for their diligent reviewing of our paper. Furthermore we thank the participants of 7th IESE Entrepreneurship Research Workshop for their detailed feedback on our research.

Correspondence concerning this article should be addressed to Florian Kunze, University of Konstanz, Postbox D87, 78457 Konstanz, Germany. E-mail: florian kunze@uni-konstanz.de
2008, 2010). Knowledge of the role of employees' subjective age for organizational behavior and outcomes is therefore limited. Following organizational scholars' recent calls to go beyond chronological age (Heckhausen, Wrosch, \& Schulz, 2010; Kooij, de Lange, Jansen, \& Dikkers, 2013; Schwall, 2012), and considering that both countries (Peeters \& Groot, 2012) and organizations (Toossi, 2012) face an increasingly older workforce, we aim in this study to obtain theoretical and empirical insight into the occurrence, antecedents, and consequences of subjective age in organizations.

Subjective age is the conclusion of a process in which individuals anchor and adjust their personal age perceptions in comparison with their chronological age. In this process, they may use personal characteristics such as perceived health, events such as birthdays and retirement, as well as benchmarks of their life stage and internal models of development (Montepare, 2009). In an organizational context, anchors and benchmarks are provided by the organization's age norms, representing people's shared beliefs about the typical ages of employees at a certain position (Lawrence, 2004). In addition, organizational processes of collective sensemaking (Maitlis \& Christianson, 2014) social comparison (Greenberg, Ashton-James, \& Ashkanasy, 2007), and attractionselection attrition cycles (Schneider, 1987) may influence how organizational members experience their subjective age. Thus, although personal factors shape the individual's experience of subjective age, considerable overlap may exist in the extent to 
which subjective age differs from chronological age among employees in an organization. Therefore, as suggested by Lawrence (2004), how old you feel also depends on where you work. We therefore conceptualize relative subjective age on the collective level as the average differences between the employees' perceived subjective age and their chronological age throughout an organization.

Two theoretical perspectives help us understand how average relative subjective age relates to organizational outcomes. First, selection, optimization, and compensation theory (SOC; Baltes \& Baltes, 1990) suggests that over the life span, the extent to which employee behavior is shaped by a "growth and promotion orientation" will decrease, and the extent to which it is shaped by a "maintenance and prevention orientation" will increase (Ebner, Freund, \& Baltes, 2006; Kooij et al., 2013). Second, socioemotional selectivity theory (SST; Carstensen, Isaacowitz, \& Charles, 1999) explains that during the life span, individuals' time perspective shifts from an unlimited to a limited future time perspective, which in turn influences the extent to which they focus on new opportunities (Zacher \& Frese, 2009; Zacher \& Frese, 2011). Although both SOC and SST have been primarily assessed in relation to chronological rather than subjective age, their logic suggests that when employees through an organization perceive to be on average younger than their chronological age, they will sustain a growth and maintenance orientation, as well as an open future time perspective, for a longer period of time. Both are key prerequisites to invest in instrumental performance-related goal accomplishment. Increased individual goal accomplishment of all employees, in turn, can be expected to increase the overall company performance (Huselid, 1995).

In a dynamic external environment, employees may need such growth- and promotion-oriented behavior even more to achieve their goals (Pulakos, Dorsey, \& White, 2006). Our reasoning thus suggests that the relationships of average relative subjective age with average individual goal accomplishment and company performance should be even more pronounced in more dynamic environments. Therefore, we assess environmental dynamism as a moderator of these relationships.

Based on our prior reasoning that the organizational context shapes employees' subjective age, we find it relevant to also investigate antecedents of relative subjective age in organizations. Lawrence's (2004) work on age norms suggests that employees adjust their subjective age by comparing themselves with a set of age norms and age stereotypes present in their organization (see also Barnes-Farrell \& Piotrowski, 1991). We reason that a key organizational input factor for such comparisons is the work content, and specifically, the perceived meaningfulness of the performed tasks (Thomas \& Velthouse, 1990). When employees perceive their task as highly meaningful, this may be expected to increase organization-based satisfaction and overall optimism, which has been related to a lower relative subjective age (Teuscher, 2009).

If this theoretical argumentation holds true, the relationship between average work-related meaning and average relative subjective age should be even more pronounced if so-called ageinclusive human resource (HR) practices (Boehm, Kunze, \& Bruch, 2014) are executed in companies. Age-inclusive HR practices are specific HR management practices that ensure that all employees, irrespectively of their age, can develop their knowledge skills and abilities, can be equally motivated, and have the same opportunities to contribute to organizational goals (Boehm et al., 2014). Such age-inclusive HR practices create a climate of positive age diversity throughout the company (Boehm et al., 2014). This will make negative age stereotypes and age norms less important criteria for employees' subjective age formation, and should thus favor the relationship between average work-related meaning and average relative subjective age. In sum, we develop and test a new theoretical model on the antecedents and consequences of average relative subjective age in organizations, as illustrated in Figure 1.

\section{Theory and Hypotheses}

\section{Relative Subjective Age in Organizations}

Subjective age refers to an individual experience of being of a certain age and can, therefore, be different from a person's chronological age. For understanding the way in which subjective age can shape subsequent behaviors, researchers have often assessed

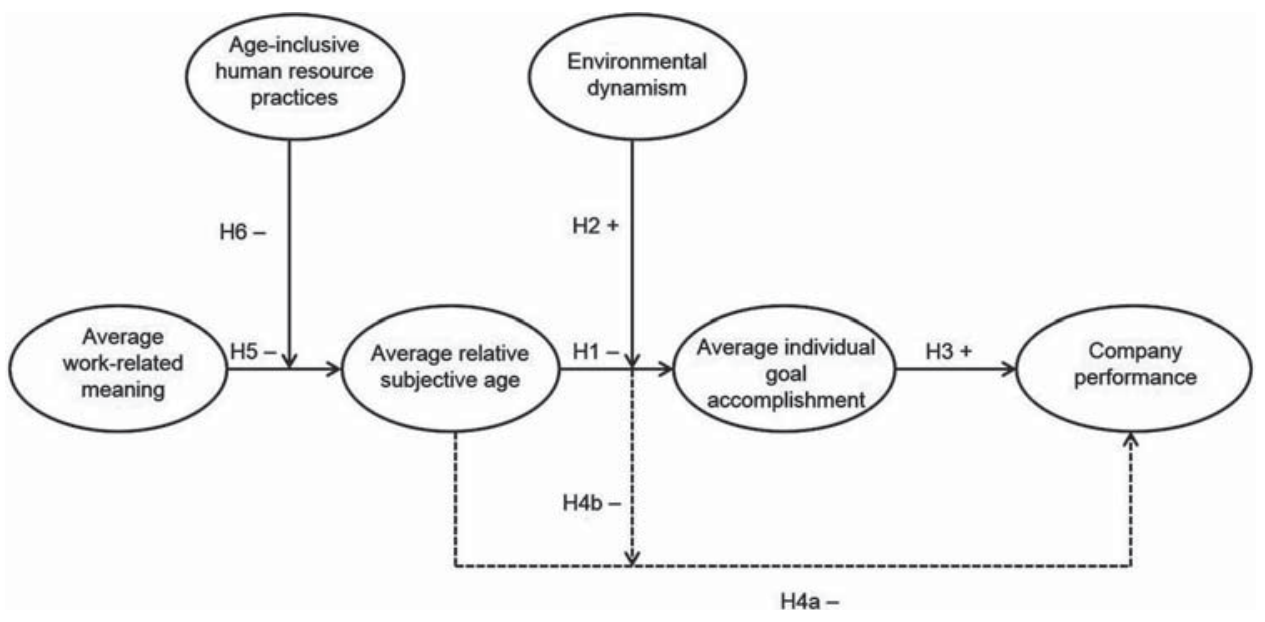

Figure 1. Conceptual model. 
the difference between a person's subjective and chronological age (i.e., Barnes-Farrell \& Piotrowski, 1989; Guiot, 2001; Stephan, Demulier, \& Terracciano, 2012). This "relative subjective age" contains key information about a person's self-image and age identity (Barak, 1998), which subsequently relates to individual attitudes and behavior (Teuscher, 2009).

Several empirical studies have shown that most people experience themselves to be younger than their chronological age, with the exception of people under 25 years, who often experience themselves as older (Galambos, Turner, \& Tilton-Weaver, 2005; Rubin \& Berntsen, 2006). This observation is in line with researchers' theorizing that a younger relative subjective age can be seen "as a special case of self-enhancement, since to feel, look, and act young is generally considered to be something positive" (Teuscher, 2009, p. 23; see also Guiot, 2001). Studies have shown that such age-related self-enhancement may have benefits in terms of health, vitality, and productivity (Montepare, 2009; Stephan et al., 2012). A desire for self-enhancement in general is also prevalent in many organizations (Dutton, Dukerich, \& Harquail, 1994; Pfeffer \& Fong, 2005).

Various organizational aspects contribute to shaping an employee's relative subjective age. First, organization-specific age norms, or "people's shared beliefs about the typical ages of individuals within a given position" (Lawrence, 2004, p. 991), provide a benchmark for people to determine their relative subjective age. For example, employees who make significant career progress after their fiftieth birthday might experience that their organization departs from common age norms that organizational careers have to be made in one's middle age (i.e., 30-50 years).

Second, collective sensemaking (Maitlis \& Christianson, 2014) and social comparison (Greenberg et al., 2007) processes provide a setting in which employees start to interpret their relative subjective age in a similar way. For example, over time employees will start to compare their subjective age identities with those in a similar chronological age group in their organization and also start to feel and behave younger or older compared with their chronological age based on these collectivelly agreed organizational age standards. Third, through cycles of attraction, selection, and attrition (ASA; Schneider, 1987) organization-specific interpretations of subjective age may become embedded in organizational processes because organizations will attract, recruit, and select employees who fit in their relative subjective age identities.

\section{Average Relative Subjective Age and Average Individual Goal Accomplishment}

For the first hypothesis, we argue that the average level of relative subjective age is positively related to the average level of employees' goal achievement in organizations based on SOC (Baltes \& Baltes, 1990) and SST theories (Carstensen et al., 1999). SOC theory proposes that people's motivational focus and choice for allocation of core resources in their work life gradually shifts from a growth and development orientation in younger years to a maintenance and loss-reduction orientation later on (Kooij et al., 2013; Kooij, De Lange, Jansen, Kanfer, \& Dikkers, 2011). Although SOC researchers have mostly used chronological age in their assessments, the underlying logic suggests it is people's perception about their age that drives effects on subsequent behavior. This implies that employees with a lower relative subjec- tive age should stay longer in the growth and maintenance phase and allocate their resources more often to the achievement of instrumental goals, compared with employees with a higher relative subjective age.

SST provides an additional theoretical argument, building on the notion of "future time perspective" (Carstensen et al., 1999). Researchers have illustrated that people typically perceive an open-ended future time perspective in younger years and a limited future time perspective in older years (Zacher \& Frese, 2009; Zacher \& Frese, 2011), which, for example, leads to lower interest of older employees in development and training opportunities $(\mathrm{Ng}$ \& Feldman, 2012). Also for SST, researchers have typically used chronological age as the dimension for assessing when people should be classified as "young" or "old," although the underlying logic suggests that age (also) needs to be experienced for driving the effects. Thus, employees with a lower relative subjective age may perceive that a significant part of their work life is still ahead of them compared with those with a higher relative subjective age. Employees with a lower relative subjective age would, therefore, invest comparatively more resources in achieving instrumental goals, whereas employees with a higher relative subjective age would put more resources into social goals, such as good social relationships, because those are immediately rewarding (Carstensen et al., 1999; Gielnik, Zacher, \& Frese, 2012; Lang \& Carstensen, 2002).

The nature and effects of SOC and SST mechanisms on how employees pursue goals and invest resources can be expected to become relatively similar over time within an organization. First, specific age norms (Lawrence, 1988, 2004) tend to develop in organizations, thus affecting the relative subjective age and, in turn, also the average SOC and SST behaviors, which should thus differ considerably between companies. For example, within a high-tech start-up, subjective age norms may dictate that employees experience themselves to be young, dynamic, and "a kid at heart." Second, through processes of collective sensemaking (Maitlis \& Christianson, 2014) and social comparison (Greenberg et al., 2007), employees assess and adjust their subjective age in relation to others in the same chronological age group and then adjust their SOC and SST related behaviors accordingly. Third, ASA mechanisms (Schneider, 1987) will favor the selection and retention of employees with a similar relative subjective age, which should, over time, lead to workforces with similar SOC- and SST-related behaviors based on their age identities.

Finally, a low relative-subjective age might not only affect goal accomplishment behaviors throughout the company through the cognitive adaption processes of older and middle-aged employees, but also through social processes that favor average goal accomplishment behaviors might be intensified. This might in particular affect the performance of young employees (i.e., below 25 years) within the company, even though this age group typically perceives a higher or equal subjective than chronological age (Galambos et al., 2005). In many organizations, these young employees are often stereotypically labeled key performing employees with the most promising career and development opportunities of all age groups in an organization (Posthuma \& Campion, 2009). When middle- and older-aged employees with a lower subjective age challenge this role and position of the chronologically young employees, these young employees may have to invest extra effort in goal achievement to sustain their position. As a consequence, 
we further suggest that young employees might show higher levels of goal accomplishment in companies with an overall low relative subjective age. Based on this overall line of argument, we suggest the following hypothesis:

Hypothesis 1: Average relative subjective age is negatively related to average individual goal accomplishment in companies.

\section{The Moderating Role of Environmental Dynamism}

Extending our prior theorizing, we are now proposing that the relationship between average relative subjective age and the average goal accomplishment of employees in companies may depend on organizational context factors, and specifically, the degree of environmental dynamism. Environmental dynamism refers to the amount of change and the level of predictability of change in the external environment of a company (Dess \& Robinson, 1984). Highly dynamic environments may be characterized, for example, by fluctuation in customer preferences, short product life cycles, and constant change of production methods (Jansen, Van Den Bosch, \& Volberda, 2006). Companies operating in highly dynamic environments might especially require that their employees of all chronological age groups invest high levels of resources to reach their instrumental goals, because these dynamic situations require that employees remain cognitively and emotionally flexible and willing to invest in knowledge acquisition to ensure goal accomplishment (Pulakos, Arad, Donovan, \& Plamondon, 2000; Pulakos et al., 2006). As a consequence, based on the reasoning from SOC theory (Baltes, \& Baltes, 1990), if on average the employees have a strong promotion-oriented focus, they might be better able to deal with such challenges. In addition, also an open-end future time perspective, as proposed by the SST theory (Carstensen et al., 1999) for relatively young employees, should be especially helpful for reaching high levels of individual goals in companies operating in dynamic environments. As such, employees in companies with a relative low subjective age might have a stronger motivation and better perceived capabilities to handle challenging situations in a dynamic environment and thus a higher chance to reach their individual goals.

If, in contrast, the external environment of the company is more stable, a higher relative subjective organizational age, with employees throughout a company focusing their behavior more on prevention and maintenance as well as on achieving goals that are more emotionally satisfying, might be sufficient to at least not experience any performance losses. As a consequence, in more stable environments, it might be sufficient for aging employees to show their age-conforming behavior (i.e., prevention and maintenance focus; focus on emotionally rewarding goals) to reach their individual goals. In sum, we thus propose the following moderation hypothesis:

Hypothesis 2: Environmental dynamism moderates the relationship between average relative subjective age and average individual goal accomplishment such that the relationship is only significant when environmental dynamism is high and nonsignificant when environmental dynamism is low.

\section{Average Individual Goal Accomplishment and Company Performance}

Following the idea that "people make the place" (Schneider, 1987 ) in organizations and that the workforce is one of the most important factors driving a company's performance (Huselid, 1995; Yukl, 2008), we argue that the average goal accomplishment of employees can be expected to be a core driver of overall company performance. That is, when employees throughout the company show increased productive behavior expressed through high levels of goal accomplishment, it should relate positively to the general performance levels of these companies. Following this logic, we propose the following hypothesis:

Hypothesis 3: Average individual goal accomplishment is positively related to company performance.

\section{Indirect Relationship Between Average Relative Subjective Age and Company Performance}

Combining the theoretical arguments we have developed so far, we argue that the average individual goal accomplishment functions as a mediator between average relative subjective age and overall company performance. More specifically, we propose that it requires a "behavioral step" to translate the growth and promotion orientation (Kooij et al., 2013) and the open-end future time perspective (Zacher \& Frese, 2009) of relatively younger employees into better general productivity of the whole company. The average level of goal accomplishment should be such a behavioral mechanism that puts the perceived better cognitive potentials of relative younger employees into concrete action that increases the overall company performance. Taking these arguments together, we propose the two following hypotheses about the indirect relationship between average relative subjective age and company performance.

Hypothesis 4a: Average relative subjective age is indirectly related to company performance through the mediation of average individual goal accomplishment.

Hypothesis $4 b$ : Environmental dynamism moderates the indirect relationship between average relative subjective age and company performance mediated through average individual goal accomplishment, such that the indirect effect is significant for high levels of environmental dynamism and nonsignificant for low levels of environmental dynamism.

\section{Average Work-Related Meaning and Average Relative Subjective Age}

Given the expected organizational performance consequences of average relative subjective age, we are also interested in obtaining insight into antecedents that shape age discrepancies in organizations. Experimental studies in the gerontology literature have shown that antecedents, such as perceived health (Hubley \& Russell, 2009) and socioeconomic status (Barrett, 2003), affect age identities.

For work settings, Barnes-Farrell and Piotrowski (1989), argued, in line with our theoretical propositions from Hypothesis 1, that the discrepancies between employees' chronological age and 
subjective age could be explained through their perceptions of alignment or misalignment with common-age stereotypes or age norms. Numerous studies have illustrated that many, and often negative, age stereotypes exist in the workplace that associate aging with a decline of work-related abilities and performance (i.e., Posthuma \& Campion, 2009). Although these stereotypes are often proved to be empirically unfounded (Ng \& Feldman, 2012), they restrict aging workers opportunities regarding training, promotion, and career development (Rosen \& Jerdee, 1976) and thus may lead to assignments of less challenging and meaningful tasks to them. This should be worrisome, as Barnes-Farrell and Piotrowski (1989) argue that "interesting, involving work tasks may slow the perception of aging" (p. 377).

As a consequence, we argue that average work-related meaning, defined as "value of work goal or purpose, judged in relation to an individual's own ideals or standards" (Spreitzer, 1995, p. 1443), is negatively related to the average relative subjective age in companies. In particular, we propose that, if employees perceive their work as meaningful, it should lower their subjective age perceptions in relation to their chronological age, no matter whether they are young or old. As a result, aging employees with meaningful tasks should perceive a large gap between common negative age stereotypes and organizational age norms (i.e., aging workers have less potential and get assigned to lower-status jobs with less purpose) for their age group and their own age identity perception, which should lead to an overall lower relative subjective age.

We would assume that the average perceived meaning should differ between companies and that some companies (i.e., a small IT start-up company) should have meaningful tasks for most of its employees, while other companies (i.e., a rather large and bureaucratic automotive supplier) might have a larger number of less meaningful jobs (i.e., administrative and routinized production tasks) to which especially aging employees might be assigned before they enter early retirement programs. Based on these arguments, we think it is plausible to propose an organizational-level relationship between work-related meaning and relative subjective age:

Hypothesis 5: Average work-related meaning is negatively related to average relative subjective age in companies.

\section{The Moderation of Age-Inclusive HR Practices}

Building on our theoretical logic from the prior hypothesis about how average work-related meaning relates to average relative subjective age, we also suggest that specific age-related HR practices are an important boundary condition for this relationship. In particular, we argue that the psychographic measure (Teuscher, 2009) of average work-related meaning is only relevant for the average relative subjective age within a company if age-inclusive HR practices support it. Age-inclusive HR practices are specific HR management practices, which ensure that all employees irrespective of their age develop their knowledge skills and abilities, become equally motivated, and receive the same opportunity to contribute to organizational goals (Boehm et al., 2014). Researchers have shown that such HR practices are related to organizational performance through a positive age-diversity climate as a mediator (Boehm et al., 2014).

Within our theoretical model, we propose that age-inclusive HR measures should favor the hypothesized effect of average work- related meaning because they create a climate to support age diversity and prevent the age-based biases (especially those against older employees) that are apparent in many companies (Kunze, Boehm, \& Bruch, 2011). If there is no age-related discrimination (i.e., such as by offering training opportunities to all employees, including those of higher age) and if an overall age-inclusive climate is present within a company, negative self-perceptions regarding an employee's personal age should further decrease. In companies in which employees are less confronted with age-based stereotypes and discrimination, they should be less prone to consider such negative age-stereotypes as a base for defining their age identity. As a consequence, employees will depart from a more positive age-concept to form their own subjective age in relation to their chronological age. In these companies, a purposeful and meaningfulness task will thus allow them to define an even lower their subjective age identity compared with companies, which constantly confronts its employees with age-biased work environments expressed through age-biased HR measures. Thus, we assume that the positive effect of work-related meaning on relative subjective age is bound to occur only in companies with ageinclusive HR practices.

If no age-inclusive HR practices are present, age-based discriminatory behavior is likely to happen within the company, and age-based stereotypes should get more apparent and obvious, increasing the risk that they negatively influence employees' relative subjective age. Thus, through institutionalized actions and behaviors, members of this company might constantly perceive that their age affects their career and reward potentials. As a result, employees would be less able to develop a self-concept of a subjective age that differs from the existing negative agestereotypes, which might cancel out the positive effect of workrelated meaning on relative subjective age. Accordingly, we propose the following hypothesis:

Hypothesis 6: Age-inclusive HR practices moderate the relationship between average work-related meaning and average relative subjective age such that the relationship is significant when the age-inclusive HR practices are high and nonsignificant when age-inclusive HR practices are low.

\section{Method}

\section{Sample}

Data for this study was collected as part of a larger research project. ${ }^{1}$ For this study, we used data from 107 companies who agreed to participate and provided sufficient information on the study's variables. For their participation, they received a benchmarking report about their applied HR practices. The sampled companies had on average 292 employees $(S D=506)$ and represented five main industry sectors: production $(22 \%)$, wholesale $(11 \%)$, retail $(4 \%)$, service $(56 \%)$, and finance $(10 \%)$.

To control for a common source bias (Podsakoff, MacKenzie, \& Podsakoff, 2012), we had three unique data sources: (a) a survey of all employees, (b) a survey of the top HR representatives in each

\footnotetext{
${ }^{1}$ Two other studies (Kunze, Boehm, \& Bruch, 2013; Raes, Bruch, \& De Jong, 2013) have used the same data set.
} 
company, and (c) a survey of members of the top management team. First, all employees received a standardized e-mail invitation from their HR department, which described the study purpose and redirected them to a Web-based survey page where they could fill out the survey. The information about the demographics (i.e., age, subjective age, and tenure), as well on the percentage of goals accomplished, was captured from all employees, whereas the information about the work-related meaning was only collected from a randomly selected $25 \%$ within each company to reduce the overall number of questions that each member had to answer. Overall, we surveyed 15,164 employees representing a within organizational response rate of $66 \%(S D=22)$. The participating employees were on average 38 years old, had an organizational tenure of 7 years, and were mostly male $(52 \%)$. As expected, the average subjective age varied across different age groups. Employees younger than 30 years felt younger only slightly ( -.24 years), whereas very young ones (i.e., younger than 25 years) felt slightly older (.90 years). The middle age group (30-49 years) felt, on average, 5.21 years younger compared with their chronological age while the employees aged 50 and older felt 8.36 years younger compared with their chronological age. Across all age groups, employees perceived to be 4.41 years younger than their chronological age.

Second, the top HR representative in each company was asked to describe specific HR practices (i.e., age-inclusive HR practices), environmental dynamism, and several control variables (i.e., industry affiliation, company size, staff shortage, economic situation, and absenteeism days per employee). The HR representatives were, on average, 45 years old, had an average organizational tenure of 11 years, and were mostly male $(67 \%)$.

Third, we captured information on the overall company performance from the members of the top management team in each company. We surveyed, on average, three top management team members per company (range $=1-14$ ). The top managers were, on average, 46 years old, had an organizational tenure of 12 years, and were mostly male $(85 \%)$.

\section{Measures}

Unless stated otherwise, 7-point rating scales $(1=$ strongly disagree, 7 = strongly agree $)$ were used. To justify the aggregation of individual measure at the organizational level, we inspected common aggregation statistics, such as the $r_{w g}$ (James, Demaree, $\&$ Wolf, 1984) and intraclass correlation coefficients $\left(\right.$ ICC $_{1}$ and ICC $_{2}$; Bliese, 2000).

Average work-related meaning $\left(\alpha=.94 ; \mathrm{ICC}_{1}=.07, p<\right.$ $.001 ; \mathrm{ICC}_{2}=.71$; median $\left.\boldsymbol{r}_{w g}=.80\right)$. We used the three-item measure of work-related meaning developed by Spreitzer (1995) as part of her empowerment scale. A sample item was, "The work I do is important to me." The individual answers were averaged as an additive model (Chan, 1998) to form one aggregated measure per company.

Average relative subjective age $\left(\mathrm{ICC}_{1}=.02, p<.001\right.$; $\mathrm{ICC}_{2}=.62$; median $\boldsymbol{r}_{w g}=.96$ ). To operationalize this measure, we asked all employees to report their chronological as well as their subjective age. The subjective age was measured by asking each employee how old he or she feels independently of his or her real age (Caudroit, Stephan, Chalabaev, \& Le Scanff, 2012; Westerhof, Barrett, \& Steverink, 2003). For the subjective age measure, the chronological age was subtracted from the subjective age (i.e., Barnes-Farrell \& Piotrowski, 1989; Guiot, 2001; Stephan et al., 2012). A negative value indicated that an employee felt younger compared with his or her chronological age, and a positive value indicated that an employee felt older compared with his or her chronological age. We averaged these values as an additive model (Chan, 1998) at the company level to form an aggregated measure of subjective age per company. ${ }^{2}$

Average individual goal accomplishment $\left(\mathrm{ICC}_{1}=.02, p<\right.$ .001 ; $\mathrm{ICC}_{2}=. \mathbf{6 2}$; median $\boldsymbol{r}_{w g}=\mathbf{. 6 1}$ ). To assess the level of goals accomplished, we used one item, which asked each employee how many individual goals agreed upon with his or her direct supervisor he or she reached in the first half of the given year $(0-100 \%)$. Again, these individual answers were averaged as an additive model (Chan, 1998) on the organizational level.

Company performance $\left(\alpha=.70, \mathrm{ICC}_{1}=.37, p<.001\right.$; ICC $_{2}=.70$; median $\left.r_{w g}=.86\right)$. In line with other studies (Delaney \& Huselid, 1996), we measured company performance as a multidimensional construct consisting of various performance dimensions, including financial performance, employee productivity, efficiency of business procedures, and employee retention. Following other studies (Rogers \& Wright, 1998), we asked the top management team members to assess the company performance by directly comparing it to their industry rivals on a 7-point scale $(1=$ far below average; $7=$ far above average $)$. For the 64 companies in which more than one top management team member answered, we calculated pertinent aggregation indices (as reported earlier) to justify the applied aggregation procedure.

Age-inclusive HR practices $(\boldsymbol{\alpha}=\mathbf{. 6 2})$. To operationalize this measure, we used the five-item scale developed recently by Boehm and colleagues (2014). This scale captures various domains of organizational HR practices for developing an age-inclusive workforce. The top HR representative of each company was asked to assess whether his firm offers (a) age-neutral recruiting activities; (b) equal access to training and further education for all age groups; (c) equal opportunities to be promoted, transferred, and to make further career steps irrespective of one's age; (d) training and education for managers on how to deal with an age-diverse workforce and how to respond to the needs of different age groups; as well as (e) the promotion of an age-friendly organizational culture.

Environmental dynamism $(\boldsymbol{\alpha}=\mathbf{. 7 4})$. The information on the company's environment was assessed by asking the top HR representative two questions adapted from the scale of Jansen, van den Bosch, and Volberda (2006). The questions are: (1) In our market, products and services to be delivered change very often $(1=$ totally disagree $; 7=$ totally agree $)$, and ( 2$)$ In our market, the methods to produce products and services change very often $(1=$ totally disagree; $7=$ totally agree $)$.

\footnotetext{
${ }^{2}$ Furthermore, we also established discriminant validity of the new measure and the conceptually related construct of self-efficacy. To measure self-efficacy, we used 4 items out of the general self-efficacy scale developed by Chen, Gully, and Eden (2001). First, the relative subjective age and the self-efficacy measure were only modestly correlated $(r=.18 ; p=$ .06). Second, also a $\chi^{2}$ difference test for a model that constrained the correlation between the two measures to unity (1) and a model that allowed free correlations showed that the model with free correlation was better fitting $\left(\Delta \chi^{2}=58.98, \Delta d f=1, p<.001\right)$. In sum, these tests indicate that self-efficacy and relative subjective age are two distinct constructs.
} 
Controls. In addition to the main study variables, we also controlled for a number of other factors that could relate to the study's outcome variables and provide alternative explanations. First, we controlled for company size in terms of the number of employees (reported by the HR executives), because this might be related to employee attitudes and behaviors, as well as company performance (Ragins, Cotton, \& Miller, 2000). Second, we controlled for company age (years since the foundation of the company), because this factor has shown to affect performance (Choi $\&$ Shepherd, 2005). Third, we also included the average organizational tenure as a control variable because not only average relative subjective age but also the experience of the employees might affect the level of individual goal accomplishment (Quinones, Ford, \& Teachout, 1995). Fourth, because other studies have shown that age diversity is related to organizational performance (Ilmakunnas \& Ilmakunnas, 2011; Kunze et al., 2013), we decided to include it as control. Fifth, we also controlled for the current economic situation in the company, as assessed by the top HR representative (How problematic is the current economic situation at the location of your company, compared with other locations? $1=$ not problematic $; 7=$ very problematic), because this might affect the company's performance. Sixth, we also examined whether the company was experiencing staff shortage, because this could affect both a company's age structure, as well as the overall performance (Homer \& Griffin, 2006). We asked the top HR representative whether he or she agrees with the statement, "We are currently not able to complete orders/services because of a shortage of staff" ( $1=$ totally disagree; $7=$ totally agree $)$. We also controlled for the average number of absenteeism days because of health-related problems per employee, as reported by the HR executives, because physical constitution might be another driver of subjective age (Hubley \& Russell, 2009). Seventh, we also account for the how potential effects of physical and/or mental handicaps might affect the perceived age in organizations by controlling for the percentage of employees per company that reported to have disabilities. Finally, we included affiliation with five industry sectorsproduction, wholesale, retail, service, and finance-as dummy control variables, because industry affiliation can be related to organizational effectiveness (Dickson, Resick, \& Hanges, 2006).

\section{Analytical Techniques}

To inspect the proposed hypotheses at the organizational level of analysis, we applied Structural Equation Modeling (SEM) techniques with the statistical package AMOS 20. As input for the SEM models, we used covariance matrix based on pairwise deletion. In line with the recommendation by Anderson and Gerbing (1988), we tested the measurement and structural relationships in two subsequent steps to prevent biased results. The interaction terms were modeled as standardized product terms of the manifest variables in the SEM models, and the interaction effects were also graphically inspected. To examine the mediation effect, we applied the procedure described by Taylor, MacKinnon, and Tein (2008) and used bootstrapping techniques to test for the indirect relationship directly. Finally, to inspect the conditional and unconditional indirect effects, we used a procedure similar to the one described by Preacher, Rucker, and Hayes (2007) for regression analyses, and tested several additional SEM models with low $(-1 S D)$ and high (+1 $S D)$ deviation of the moderator.

\section{Results}

Table 1 shows the intercorrelations and descriptives (mean and $S D$ s) of the study's variables. For completeness, the correlation table also includes the relationship between the single factors of average chronological age and average subjective age, although they are not included in the main model. In line with Hypothesis 1 , average relative subjective age was negatively related to average individual goal accomplishment in companies, $r=-.31, p \leq$ .001 . As proposed by Hypothesis 3, average individual goal accomplishment was positively related to company performance, $r=$ $.27, p \leq .05$. As predicted by Hypothesis 5 , average work-related meaning was negatively related to average subjective age in companies, $r=-.24, p \leq .05$. Overall, we did not observe high intercorrelations between any of the variables that could raise concerns about multicollinearity issues.

\section{Measurement Model}

The proposed measurement model includes three latent constructs (average work-related meaning, age-inclusive HR practices, environmental dynamism, and company performance) with 14 indicators and two manifest constructs (average relative subjective age, average individual goal accomplishment). In line with advice by Bentler (2007) and Hu and Bentler (1999), for samples smaller than 200 cases, we used two incremental fit indices-the comparative fit index (CFI) and the incremental fit index (IFI)-in combination with the root mean square error of approximation (RMSEA) to evaluate the overall model fit. We applied common cutoff values-below .08 for the RMSEA (Browne \& Cudeck, 1993) and above .90 for the CFI and IFI-to assess the fit of our data to the proposed models. In addition, we used the Akaike information criterion (AIC; Akaike, 1987) to compare different model solutions, with a lower AIC value indicating a better fit.

As indicated in Table 2, the hypothesized measurement model had a good overall model fit $\left(\chi^{2}=136, d f=92 ; \mathrm{CFI}=.93\right.$, IFI $=$ .93$, RMSEA $=.07$, AIC $=256)$. In addition, it also compared favorably to three alternative models. First, alternative model 1 with all measures coming from the same source (average workrelated meaning, average relative subjective age, and average individual goal accomplishment) loading on one factor had a significantly worse fit, indicating that the three measures were distinct. Second, alternative model 2 with all outcome measures included in the model (average relative subjective age, average individual goal accomplishment, and company performance) had a worse fit. Third, alternative model 3 with the two moderators (age-inclusive HR practices and environmental dynamism) loading on one common factor showed inferior fit properties. Finally, alternative model 4 with all items loading on one common factor had a worse fit. In sum, these results strengthened our confidence in the assumed measurement structure.

\section{Structural Model}

Hypotheses testing. In the second part of our analysis, we inspected the structural relationships proposed in Hypotheses 1-6. In line with the proceeding defined for regression analysis (Aiken \& West, 1991), we first specified a model in which the moderation terms were restricted to zero, because the main effects might be 


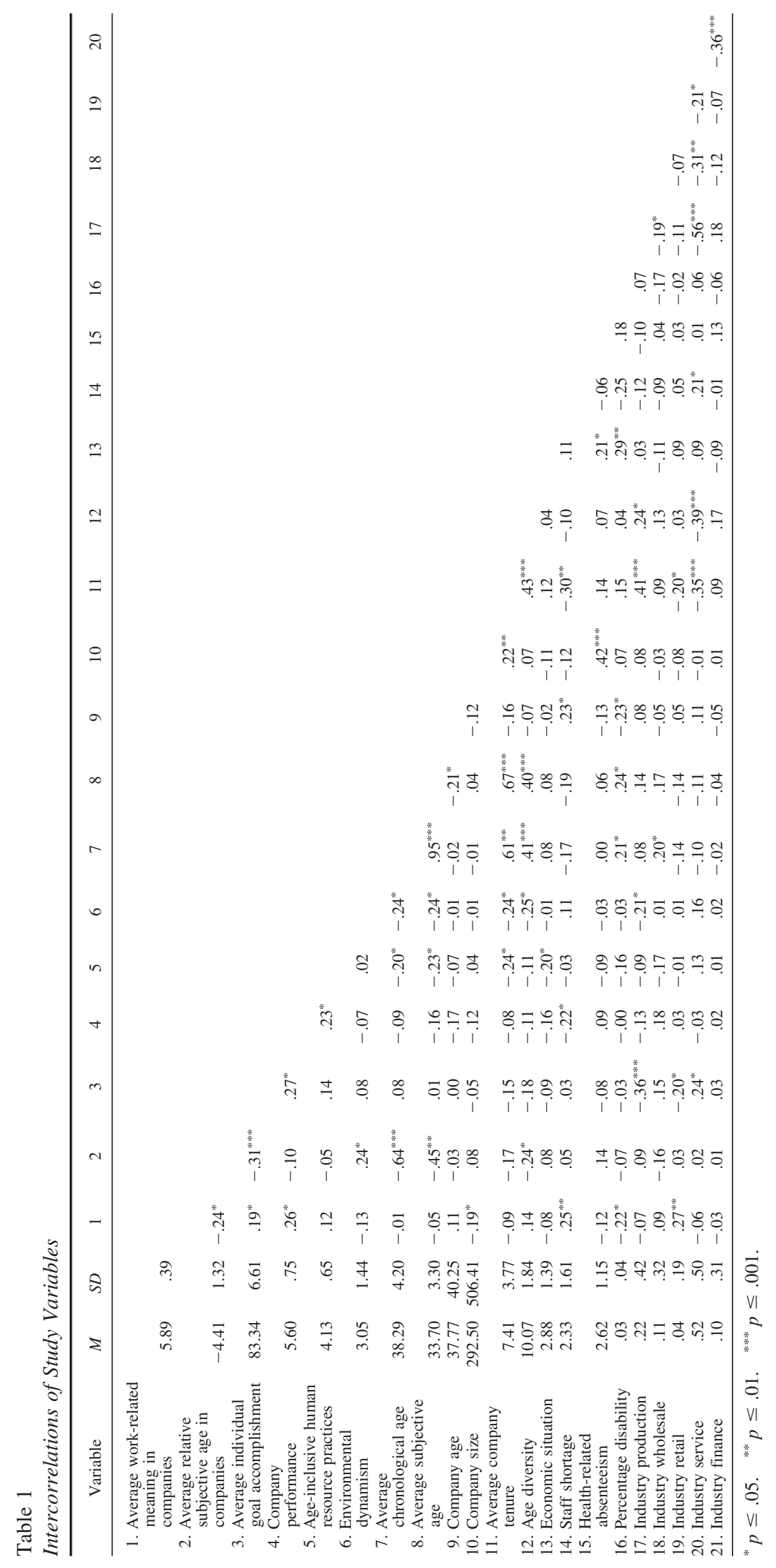


Table 2

Measurement Model Comparison

\begin{tabular}{|c|c|c|c|c|c|c|c|c|c|}
\hline Model & $x^{2}$ & $d f$ & $\chi^{2} / d f$ & $\Delta \chi^{2}$ & $\Delta d f$ & CFI & IFI & RMSEA & AIC \\
\hline Hypothesized model & 136 & 92 & 1.48 & & & .93 & .93 & .07 & 256 \\
\hline Alternative model 1: Same source one factor & 160 & 99 & 1.62 & $24^{* * *}$ & 7 & .90 & .89 & .08 & 266 \\
\hline Alternative model 2: All outcomes one factor & 165 & 100 & 1.65 & $29^{* * * *}$ & 8 & .89 & .90 & .08 & 269 \\
\hline Alternative model 3: Moderators one factor & 189 & 96 & 1.97 & $53^{* * * * *}$ & 4 & .85 & .85 & .10 & 302 \\
\hline Alternative model 4: One common factor & 303 & 99 & 3.06 & $167^{* * * * *}$ & 7 & .66 & .67 & .14 & 409 \\
\hline
\end{tabular}

Note. $\mathrm{CFI}=$ comparative fit index IFI $=$ incremental fit index; RMSEA $=$ root mean square error of approximation; AIC $=$ Akaike information criterion. $n=107$. The three alternative measurement models are compared to the hypothesized measurement model. The lowest AIC value shows the best-fitting model.

${ }^{* *} p \leq .01 .{ }^{* * *} p \leq .001$; chi-difference statistic compared with the hypothesized model.

confounded by the interaction term. In two subsequent steps, we added the two moderation terms to the model to inspect the incremental explained variance by these factors. We specified the three-path mediation model (Hypothesized model A) following the advice of Taylor et al. (2008) by including all indirect effects specified in Hypotheses 1, 3, and 5, as well as a direct relationship between the study variables (i.e., average relative subjective age and company performance). As shown in Table 3, this mediation-only model showed good model fit properties $\left(\chi^{2}=370, d f=251 ; \mathrm{CFI}=.90\right.$, $\mathrm{IFI}=.91, \mathrm{RMSEA}=.07, \mathrm{AIC}=922)$.

In this model, all hypothesized relationships were significant and in the proposed direction (for details see Figure 2). In line with Hypotheses 1 and 3, average relative subjective age was negatively linked to average individual goal accomplishment $(\beta=-.26$, $t=-2.83, p \leq .01)$, and average individual goal accomplishment was positively linked to company performance $(\beta=.22, t=1.99$, $p \leq .05){ }^{3}$ Supporting Hypothesis 5, average work-related meaning was positively related to average relative subjective age in companies $(\beta=-.24, t=-2.35, p \leq .05) .{ }^{4}$ Because all these proposed relationships were significant, we also examined whether average individual goal accomplishment mediated the indirect relationship between average relative subjective age and company performance, following the proposed Hypothesis 4a. For that purpose, we used 1,000 bootstrapping samples in AMOS, which indicated a significant positive effect of that relationship $(\beta=-.06 ; 95 \%$ bias corrected confidence interval [BCCI] $[-.182,-.001])$, fully supporting Hypothesis $4 \mathrm{a}$.

In a second step, we specified an additional model (hypothesized model $B$ ), which allowed the interaction term of average relative subjective age in companies and environmental dynamism to load on the average individual goal accomplishment measure to test Hypothesis 2. This alternative model also showed superior fit properties compared with the mediation-only model (hypothesized model $A ; \Delta \chi^{2}=4, \Delta d f=1, p \leq .05$, AIC $\left.=920\right)$. The path of the moderation term also remained significant $(\beta=-.18, t=-2.01$, $p \leq .05)$, and the explained variance in the outcome measure increased by $3 \%$. We also graphically plotted the result as illustrated in Figure 3. This graph indicates that the average relative subjective age seems to lower the individual goal accomplishment only in companies working in a dynamic environment, whereas for companies operating in a less dynamic environment, average relative subjective age and average individual goal accomplishment seem almost unrelated. This graphical findings are also supported by simple slope testing, which showed that the low environmental dynamism slope is nonsignificant $(\beta=-.18, t=-1.32, n s)$ and that the high environmental dynamism slope is negative and significant $(\beta=-.54, t=-3.02, p \leq .01)$. Furthermore, we also tested a moderation of the indirect effect between average subjective age and company performance by environmental dynamism (Hypothesis 4b). For that purpose, we specified two additional models with either high $(+1 S D)$ or low $(-1 S D)$ values of environmental dynamism and again calculated the indirect effects with 1000 bootstrapping samples. As Table 4 illustrates, in line with Hypothesis 4, the indirect effect was only significant under conditions of high environmental dynamism. When environmental dynamism was low, this effect was not significant.

In a third step, we specified a model (hypothesized model $C$ ) that allowed the interaction term of age-inclusive HR practices and average work-related meaning to load on the average relative subjective age in companies to test Hypothesis 6. Compared with the hypothesized model $\mathrm{A}$, the hypothesized model 6 showed increased fit properties $\left(\Delta \chi^{2}=4, \Delta d f=1, p \leq .05\right.$, AIC $=920$;

\footnotetext{
${ }^{3}$ Because the information on subjective age and individual goal accomplishment were collected from the same employees in each company, a common source bias might night have inflated this relationship (Podsakoff, MacKenzie, \& Podsakoff, 2012). To control for this potential issue, we executed a post hoc random sample split of our data. For that purpose, two $50 \%$ random samples were drawn in each company, one to aggregate the subjective age measure and one to aggregate the goal accomplishment measure. With those two newly formed variables from independent sources, we then specified an alternative model in which the relationship remained significant at a two-sided $10 \%$ level and in the expected direction $(\beta=-.18$, $t=-1.72, p \leq .05)$. As we proposed a directed hypothesis for that relationship, we think that one-sided significant test, which is then below the $5 \%$ threshold, is reasonable. This finding strengthened our confidence that common source bias was not a major concern for the relationship between average relative subjective age and average individual goal accomplishment.

${ }^{4}$ A similar argument as in footnote one about a potential common method bias might be raised about the relationship between average workrelated meaning and average relative subjective age, as these two measures were also collected from the same group of employees. As a consequence, we also performed a post hoc split sample approach. This time, we used the randomization procedure that was already implemented in the data collection procedure. Consequently, we used the randomly selected $25 \%$ of the employees in each company to form the average work-related meaning measure and the remaining $75 \%$ of the employees in each company to form the average relative subjective age measure. With those two newly formed measures, we then specified an alternative model in which the relationship between average meaning and average relative-subjective age remained stable and significant $(\beta=-.19, t=-2.03, p \leq .05)$. In sum, based on this robustness test, we concluded that common method variance is also unlikely to be a major bias for the relationship between average workrelated meaning and average relative subjective age.
} 
Table 3

Structural Model Comparison

\begin{tabular}{|c|c|c|c|c|c|c|c|c|c|}
\hline Model & $x^{2}$ & $d f$ & $\chi^{2} / d f$ & $\Delta \chi^{2}$ & $\Delta d f$ & $\mathrm{CFI}$ & IFI & RMSEA & AIC \\
\hline Hypothesized model A: Mediation-only model & 370 & 251 & 1.47 & & & .90 & .91 & .07 & 922 \\
\hline Hypothesized model B: Age-inclusive HR measures moderation & 366 & 250 & 1.46 & $4^{*}$ & 1 & .90 & .92 & .07 & 920 \\
\hline Hypothesized model C: Dynamic environment moderation & 366 & 250 & 1.46 & $4^{*}$ & 1 & .90 & .92 & .07 & 92 \\
\hline \multicolumn{10}{|l|}{ Nested models } \\
\hline Alternative model 1: No-controls model & 429 & 286 & 1.50 & $63^{* *}$ & 36 & .88 & .90 & .07 & 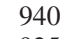 \\
\hline Alternative model 2: Reversed mediation & 367 & 250 & 1.47 & 1 & 0 & .90 & .92 & .07 & 92 \\
\hline \multicolumn{10}{|l|}{ Nonnested models } \\
\hline Alternative model 3: Mean age mediator & 377 & 260 & 1.45 & 11 & 10 & .91 & .92 & .07 & \\
\hline Alternative model 4: Chronological age as control & 381 & 260 & 1.47 & 15 & 10 & .91 & .92 & .07 & \\
\hline Alternative model 5: Average chronological age as moderator & 395 & 260 & 1.52 & $29^{* *}$ & 10 & .90 & .91 & .07 & \\
\hline
\end{tabular}

Note. $\mathrm{CFI}=$ comparative fit index; $\mathrm{IFI}=$ incremental fit index $; \mathrm{RMSEA}=$ root mean square error of approximation; AIC $=$ Akaike information criterion; $\mathrm{HR}=$ human resources. $n=107$. The hypothesized model B and C are compared with the hypothesized model A. The alternative models are compared with the hypothesized model $\mathrm{C}$.

${ }^{*} p \leq .05$. *** $p \leq .01$. **** $p \leq .001$.

Table 3). In addition, the relationship of the moderator term with average relative subjective age was significant $(\beta=-.19$, $t=-1.93, p \leq .05)$, and it increased the explained variance in average relative subjective age by $3 \%$. Figure 4 shows a graphical illustration of the moderation effect, indicating that the negative relation between average work-related meaning and relative subjective age in companies seems to be present only when the age-inclusive HR practices are high, whereas under the condition of low age-inclusive HR practices, this relationship is almost zero. These graphical observations are also supported by simple slope testing, which showed that the high slope for age-inclusive HR practices is significant $(\beta=-.49, t=-3.20, p \leq .01)$, whereas the low slope for age-inclusive HR practices is not significant $(\beta=$ $.09, t=.54, n s)$. In sum, these results fully support Hypothesis 6.

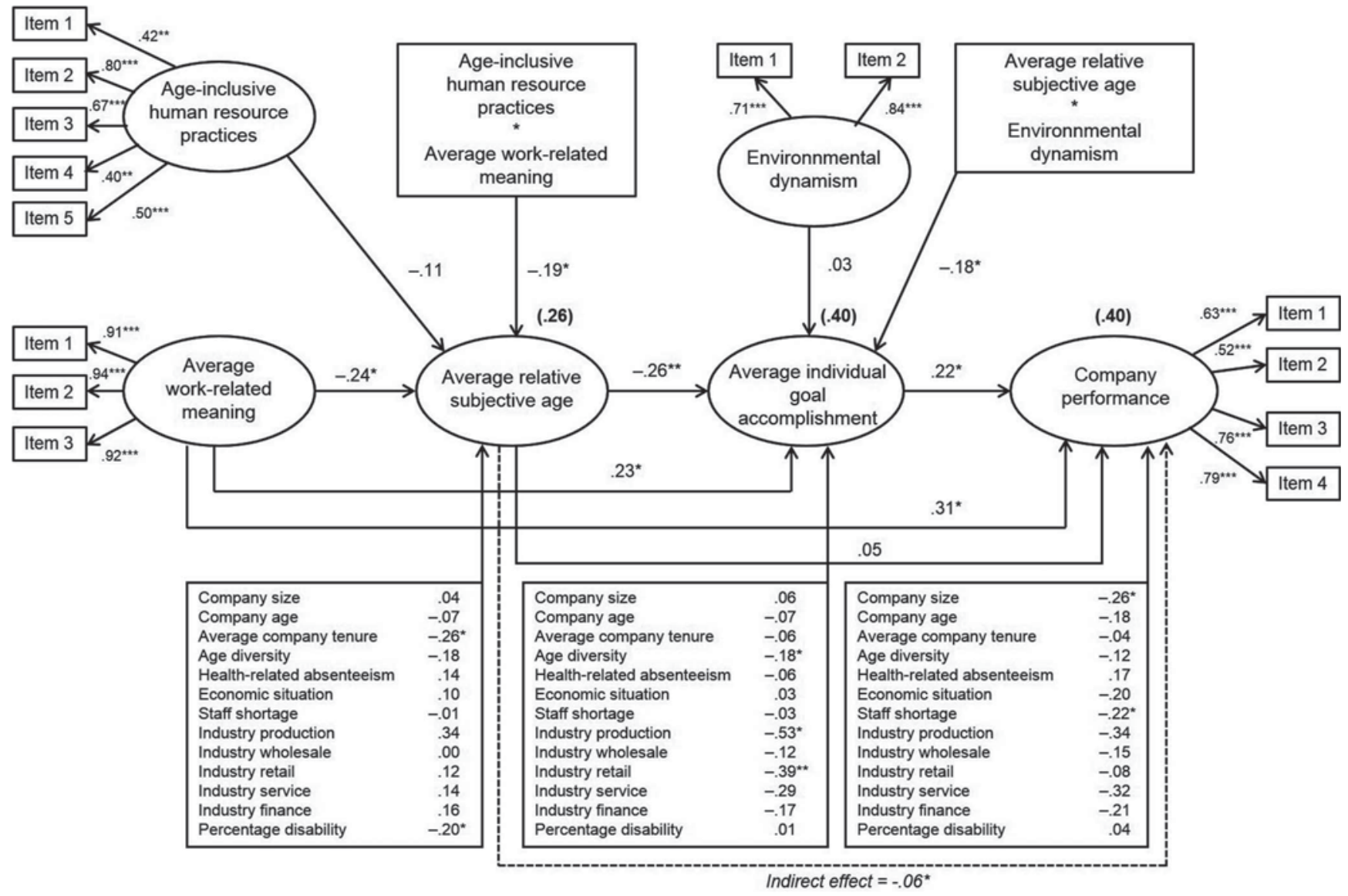

Figure 2. Summary of results. Note. $\mathrm{N}=107 ;^{* *} \leq .01,{ }^{*} \leq .05$; squared multiple correlations are in parentheses. 


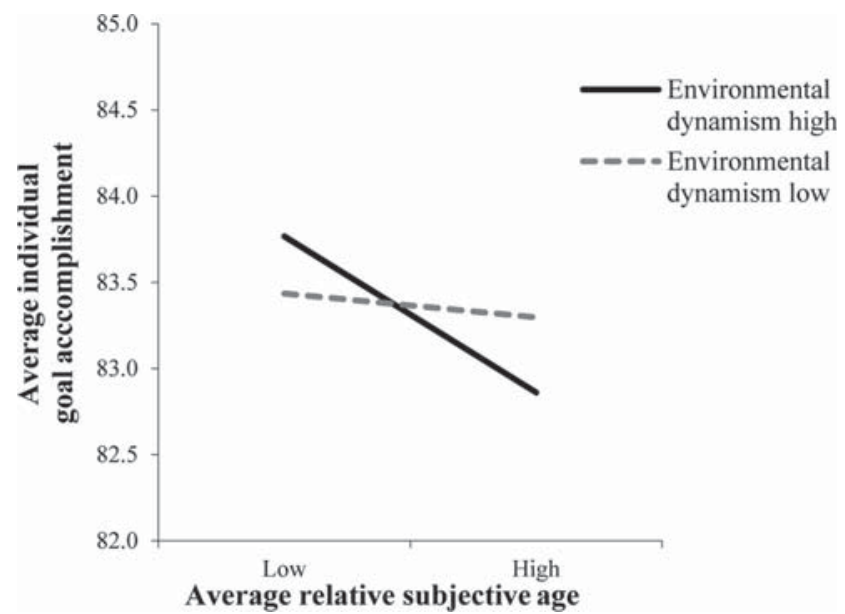

Figure 3. Moderation of environmental dynamism on the relationship between average subjective age and the average individual goal accomplishment in companies.

Robustness tests. As shown in Table 3, we also evaluated a number of alternative models to inspect the robustness of our findings. In particular, we compared our assumed superior model solution (hypothesized model C; with the lowest AIC value) with four alternative model solutions. First, a no-controls model (alternative model 1) in which all paths of the control variables to the three outcome measure were restricted to zero had a worse fit $($ AIC $=940)$. In addition, in this model, all core hypothesized relationships remained significant at the $5 \%$ level and in the right direction, ruling out the possibility of impotent control variables biasing the results. Second, an alternative model in which the order of the two process variables (average relative subjective age, average individual goal accomplishment) changed (alternative model 2) by including only the relationships among average workrelated meaning and average individual goal accomplishment, and average relative subjective age and company performance also had a worse fit $(\mathrm{AIC}=925)$.

Third, in an alternative model in which the average chronological age replaced the average relative subjective age as a focal mediator variable (alternative model 3), the indirect relationship between average individual goal accomplishment and company performance mediated through average chronological-age was not significant $(\beta=-.01 ; 95 \%$ BCCI $[.051,-.154])$. Fourth, in an alternative model that included average chronological age as a control

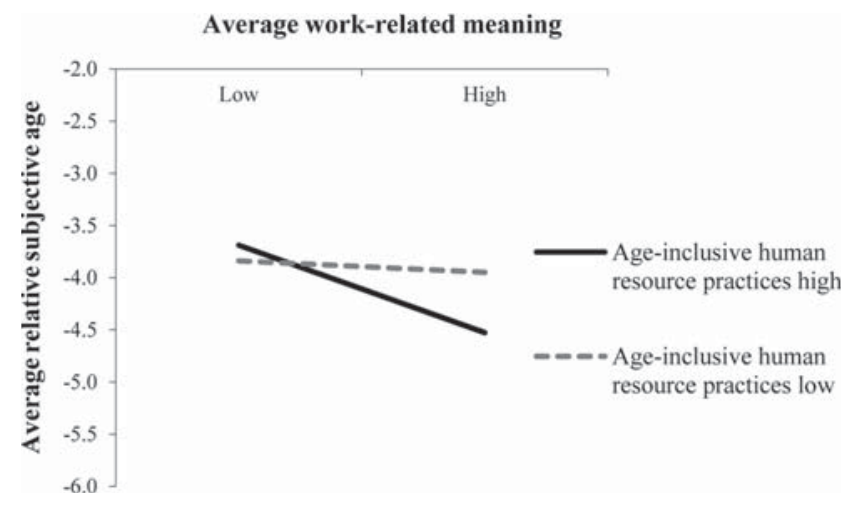

Figure 4. Moderation of age-inclusive human resource practices on the average work-related meaning/average subjective age relationship in companies.

variable (alternative model 4), the relationship between average relative subjective age and average individual goal accomplishment remained negative and significant $(\beta=-.37, t=-2.97, p \leq .01)$, and the average chronological age had no effect on the average individual goal accomplishment $(\beta=-.13, t=-1.19, n s)$. This result strengthened our confidence that indeed the relative subjective age is driving our relationship beyond any effect of chronological age. Finally, we also inspected whether the relationship of average relative subjective age with average goal accomplishment would be different in companies with a chronologically old or young workforce, by specifying an alternative model (alternative model 5) in which the employees' chronological age was specified as a moderator for that relationship. The interaction term was found to be nonsignificant $(\beta=.09, t=1.07, n s)$, indicating that the average relative subjective age relates negatively to average individual goal accomplishment, independently of the average chronological age of the workforce.

\section{Discussion}

In this study, we hypothesized, and empirically demonstrated that the average relative subjective age in companies affects the average level of successful goal accomplishment of employees, which is an important prerequisite for the overall company performance. In other words, an organizational workforce that feels younger than their chronological age benefits the performance of the company as a whole. However, this performance effect of

Table 4

Indirect Effects Under Conditions of Different Values of Environmental Dynamism

\begin{tabular}{|c|c|c|c|c|c|c|}
\hline \multicolumn{7}{|c|}{ Bootstrap results: Average relative subjective age $\longrightarrow>$ average individual goal accomplishment $\longrightarrow>$ company performance } \\
\hline \multirow{3}{*}{$\begin{array}{l}\text { Value of } \\
\text { environmental dynamism }\end{array}$} & \multirow{2}{*}{\multicolumn{4}{|c|}{ Bootstrapped point estimates }} & \multirow{2}{*}{\multicolumn{2}{|c|}{$\begin{array}{l}\text { Bootstrapped confidence } \\
\text { intervals (bias corrected) }\end{array}$}} \\
\hline & & & & & & \\
\hline & Boot & $S E$ & $Z$ & Significance & Lower & Upper \\
\hline Low & -.023 & .036 & 1.105 & .269 & -.138 & .024 \\
\hline Mean & -.058 & .042 & .823 & .041 & -.182 & -.001 \\
\hline High & -.114 & .077 & -.755 & .045 & -.319 & -.003 \\
\hline
\end{tabular}


average relative subjective age was significant only when the environment dynamism in which a company operates was high rather than low. We also identified the average level of perceived work-related meaning as an antecedent of average relative subjective age. If employees on average perceive their work to be meaningful, they are likely to feel fully integrated in the working process, which relates negatively to subjective age. This, however, only happens in companies that through age-inclusive HR practices ensure that no age-based stigmatization or biases are present.

\section{Theoretical Contributions and Future Research Directions}

This research has several important theoretical implications. First, we extend the literature on the age/job performance relationship (Ng \& Feldman, 2008) by showing that relative subjective age is more likely to relate to the average individual goal accomplishment and ultimately the performance of the company as a whole than chronological age. Our results indicate that considering relative subjective age in organizations, as a more advanced measure of age, is a promising way to move forward in this area of research. For example, it may help clarifying prior inconsistent findings in the literature on the age/job performance relationship (Ng \& Feldman, 2008; Ng \& Feldman, 2010). Previous findings have indicated that chronological age has a null or even positive relationship to job performance and other work-related outcomes, which is in contrast with the often stereotypically expected negative relationships (Ng \& Feldman, 2008; Ng \& Feldman, 2010). Our study suggests that adapting one's subjective age, as a self enhancement strategy, might help to sustain or even extend their instrumental performance behavior, so that chronological age is less consequential for work outcomes.

We note, however, that we only tested average instrumental performance related behavior as a mediator between average relative subjective age and company performance. We would speculate that other factors such as prosocial work behaviors (e.g., organizational citizenship behavior) might be related to average relative subjective age in an opposite direction (i.e., positively). Based on our conceptual reasoning using SST theory, we expect that lowering employees' relative subjective age increases the focus on long-term instrumental goals at the expenses of shortterm social and emotional rewarding goals, and that this would be positively related to prosocial work behaviors. We would encourage researchers to include prosocial work attitudes and behaviors in future studies as a competitive mediator in the relationship between average relative subjective age and company performance. In addition, given the behavior and performance consequences of average relative subjective age shown in our study, we would be interested to see more research on the measurement and operationalization of relative subjective age. While we simply asked for each employee's subjective age conception future research might consider asking how old an individual perceive to be relative to his work group and/or include the "ages of me" conception, which differentiates between look and feel age (Kastenbaum, Derbin, Sabatini, \& Artt, 1972).

Second, by developing and testing a new organizational level theoretical framework on relative subjective age, we provide a starting point for researchers who are interested in organizationallevel processes in this area. In particular, we applied SOC theory
(Baltes \& Baltes, 1990) and SST (Carstensen et al., 1999) to explain aging processes in whole organizations, whereas prior research had primarily used these theories to explain individual aging and development processes. Given our results, remaining longer in a growth and maintenance phase and keeping an openended future perspective could be a worthwhile strategy for aging employees in companies to stabilize their productive behavior and contribute to the overall performance of the organization.

Various factors may contribute to employees developing similar perceptions of age in organizations, among which are organization-specific age norms (Lawrence, 2004), collective sensemaking processes around age perceptions (Maitlis \& Christianson, 2014), social comparison processes (Greenberg et al., 2007), as well as mechanisms of attraction, selection, and attention (Schneider, 1987). In addition, the specific occupational structure of organizations may also shape common age identities: some organizations might be dominated by some specific tasks and job designs that favor a lower or higher relative subjective age of their workforces. We further explained the theoretical mechanism in aging organizational workforces by introducing environmental dynamism as a prominent organizational level moderator of the average relative subjective age/organizational performance relationship. Lowering the collective age identity through SOC and SST is especially relevant if a company operates in a dynamic environment, because this requires employees to stay flexible and adaptive in all life stages to maintain their productivity.

Third, we also add significantly to the emerging literature on the effects of age configurations on company performance (Choi \& Rainey, 2010; Ilmakunnas \& Ilmakunnas, 2011; Kunze et al., 2011, 2013). We extend the knowledge from existing studies, which considered only average chronological age and chronological age diversity as drivers of organizational processes and performance. We show that relative subjective age configurations also matter for organizational performance and even suppress the previously reported findings of chronological age. Therefore, we recommend including information on the relative subjective age in future studies on age configurations in organizations. In particular, we would find it interesting to also consider subjective age as a diversity factor in organizations. While previous research has identified age diversity as a factor that increases age-based discrimination in companies, which in turn decreases performance (Kunze et al., 2011), we would propose that subjective agediversity might lower this effect. If, for example, feeling younger is a consistent age-identity throughout an organization, it might work as a criterion that can bridge diversity (Gratton, Voigt, \& Erickson, 2007) and prevent age-based subgroup formation that is responsible for the negative effects of chronological age diversity in organizations.

Finally, we also open up a new field for research on potential antecedents of average relative subjective age in organizations. Within the theoretical logic of Barnes-Farrell and Piotrowski (1991), we argued that factors that create a discrepancy between common stereotypes for a given age group and the perceived age self-concept of the employees would lower the average relative subjective age. As the first factor at the organizational level, we introduced and empirically tested average work-related meaning as an important factor in creating a gap between common stereotypes about aging employees ("less valuable for work processes and the company overall") and the perception of the aging employees, 
which lowered the average relative subjective age. Furthermore, we also identified age-inclusive HR practices as a crucial organizational level boundary condition that enables the relationship between purposeful work content and lower subjective age to prosper by creating a positive and nondiscriminatory age climate in organizations. These HR practices seem to create an organizational environment free from age biases, enabling aging employees to form a self-concept of age, which considerably differs from their chronological age. Although we controlled for a number of other individual (i.e., health status, disability) and organizational characteristics (i.e., economic situation, diversity criteria, industry sectors) that might affect the average subjective age perceptions in companies, this list is not inclusive, given the large number of correlates of subjective age identified in gerontological research (Baum \& Boxley, 1983; Montepare, 2009). Future studies might therefore also consider other factors that might function as antecedents of average subjective age in companies. Candidates might be, for example, some obvious physical, cognitive factors such as premature balding or graying, athleticism or conscientiousness. Future researcher might inspect how some or all of these factors affect self-perceived age discrepancies in organizations (as assessed in our study) or age discrepancies as perceived by social environment (i.e., colleagues, supervisors) as a potential extension for future studies.

Furthermore, future research may also consider using experimental or quasi-experimental research designs to give organizations a lever to improve their average relative subjective age levels. Based on our conceptual framework of SOC and SST, future studies might research whether, for example, specific career development programs (i.e., a career perspective seminars for employees at the beginning of each life decade) that are implemented in some randomly selected areas of organizations might have an effect on the future time perspective and SOC behaviors in these organizational areas and thereby also impact the average relative subjective age identities.

\section{Limitations}

As in other empirical studies, our research has methodological limitations. First, the specific nature of our sample of German companies might have biased our results, because some scholars have proposed that attitudes toward age are culturally constructed and that youthfulness as a societal goal is specific for Western cultures (Catterall \& Maclaran, 2001). Following this argumentation, our sample from a Western, industrialized country might have worked in favor of our hypotheses. Recent empirical research, however, has challenged the notion of youthfulness as an exclusive Western phenomenon by showing that the concept of younger desired subjective age was prevalent in many different societies, including developed Western countries (i.e., Switzerland, United States, United Kingdom) and emerging eastern (i.e., South Korea, China, and India) and Latin American societies (i.e., Brazil) (Barak, 2009). The average difference between subjective and chronological age, however, differed from almost 10 years in the United Kingdom to only 10 months in China. In light of these results, we would highly encourage future researchers to replicate and extend our findings in multicultural samples.

Second, because our research applied a cross-sectional design, we cannot fully prevent concerns about reversed causality. This might be particularly worrisome for the core relationship of our study between average relative subjective age and average individual goal accomplishment. Therefore, we performed a further robustness test to control for a potential endogeneity bias, which is a main threat for causality (Antonakis, Bendahan, Jacquart, \& Lalive, 2010). For that purpose, we used an instrumental variable approach with two-stage least square (2SLS) estimation techniques (Antonakis et al., 2010) as a final robustness check for our results. In this 2SLS model, we used average chronological age and average organizational tenure as instrumental variables, because they showed higher correlations with average relative subjective age and lower relationships with average goal accomplishment. These two variables were then used to predict average subjective age in a first regression analysis. The $F$ statistics $(48.76 ; p<.001)$ and the $R^{2}$ value (.45) were above the threshold for weak instruments (Stock, Wright, \& Yogo, 2002). In a second step, the standardized predicted values from the first regression model were used to replace the average relative subjective age measure in a further SEM model. In this model, the relationship between the instrumented variable and average goal accomplishment remained negative and significant on a $5 \%$ level (one-sided; $\beta=-.17$, $t=-1.76, p \leq .05$ ). This result strengthened our confidence that endogeneity was not a major bias for our results and thus also causality is likely to flow in our theoretical proposed direction. Nonetheless, we encourage future researchers to replicate our study with longitudinal, experimental, and/or quasi-experimental designs.

Third, our subjective assessment of company performance might raise concerns about the validity and reliability of our central outcome measure (Starbuck, 2004). Indeed, objective and publicly available performance measures would have been a desirable source of the organizational performance measure. Unfortunately, most companies in our sample were small- to mediumsized, privately owned, and did not publish any objective performance measures. However, numerous studies have shown that subjective measures are also a valid source of company performance (Wall et al., 2004), and members of the top management team can be considered especially reliable informants for this measure. In sum, we can thus conclude that the performance measure we used is appropriate for our specific sample structure; however, future studies may apply objective performance measures, particularly for large and publically listed companies, to strengthen and extend our preliminary findings.

\section{Practical Implications}

This study also has important practical implications. First, we showed that average relative subjective age and not "merely" the average chronological age of the workforce drives performance outcomes at the organizational level of analysis. This is particularly important in light of the demographic change that confronts many companies in Western industrialized countries with an increasingly aging workforce. Our results imply that companies should perhaps worry less about the chronological aging of their employees, but rather undertake measures that stimulate their workforce to feel younger than their chronological age, especially, if they are operating in a dynamic external environment. As such, our results alter the "threat" of the demographic shift as an inevitable demographic aging of the workforce that endangers overall 
productivity to an "opportunity" that can be actively managed through organizational factors.

Our results indicate that ensuring meaningful tasks for employees from all age groups can be an important way to increase the discrepancy between chronological and subjective age throughout the company. This implies that task designs and leadership behaviors need to focus on stimulating high levels of work-related meaning. Tasks could be designed to have a high level of autonomy in decision-making and to have an effect on performanceoriented behavior through work-related behavior both inside and outside the organization (Holbeche \& Springett, 2004). Practical actions to increase the meaningfulness of a task could include job enlargement (i.e., increasing the scope of job by adding responsibilities and tasks on the same level) and especially job enrichment (i.e., redesigning a job that it is more challenging and involves less repetitive tasks; Parker, 1998). Companies should in particular focus on these actions for blue-collar, production jobs, which often involve limited variation and autonomy. In addition, executives in the organization should be sensitized for their key role in creating a meaningful work environment, since leadership is often defined as the "management of meaning" (Smircich \& Morgan, 1982).

Furthermore, our results also indicate that specific HR-practices are important boundary conditions for work-related meaning to translate into lower relative subjective age throughout a company. Therefore, companies should invest in institutionalized ageinclusive HR management practices (Boehm et al., 2014) that foster a positive attitude and climate toward age throughout the company. Companies should assess whether their recruitment policies, their training and development program, their career management systems, and their leadership trainings indeed target an age diverse workforce, signifying that employees from all age groups have equal access to these HR management practices. Concrete actions for companies may include assessing the training participation of different age groups or assessing which career paths are open and taken by which age group of their workforce. Furthermore, leadership trainings programs should explicitly address the active role of executives for creating an age bias free environment within organizations.

\section{Conclusion}

Because the workforce in most industrialized countries is rapidly aging, knowledge on the age and aging processes affecting performance outcomes in companies is a key prerequisite for future prosperity. This study developed and tested new theory, which suggests that the organizational level discrepancy between average subjective age and average chronological age matters for average goal accomplishment and ultimately the overall company performance, particularly in companies operating in a dynamic external environment. Furthermore, we also put forward theory about organizational level antecedents that affect the relative subjective age in organizations by testing whether perceived work related meaning reduces the subjective age of a company's workforce, especially if it is backed by age-inclusive HR practices. In sum, we develop a new company-level theoretical framework on average relative subjective age, which shows that the aging of the workforce can be managed actively, providing a good base for fruitful future research on the consequences of the demographic change in companies.

\section{References}

Aiken, L. S., \& West, G. (1991). Multiple regressions: Testing and interpreting interactions. Thousand Oaks, CA: Sage.

Akaike, H. (1987). Factor analysis and AIC. Psychometrika, 52, 317-332. http://dx.doi.org/10.1007/BF02294359

Anderson, J. C., \& Gerbing, D. W. (1988). Structural equation modeling in practice: A review and recommended two-step approach. Psychological Bulletin, 103, 411-423. http://dx.doi.org/10.1037/0033-2909.103.3.411

Antonakis, J., Bendahan, S., Jacquart, P., \& Lalive, R. (2010). On making causal claims: A review and recommendations. The Leadership Quarterly, 21, 1086-1120. http://dx.doi.org/10.1016/j.leaqua.2010.10.010

Baltes, P. B., \& Baltes, M. M. (1990). Psychological perspectives on successful aging: The model of selective optimization with compensation. In P. B. Baltes \& M. M. Baltes (Eds.), Successful aging: Perspectives from the behavioral sciences (pp. 1-34). New York, NY: Cambridge University Press. http://dx.doi.org/10.1017/CBO9780511665684 .003

Barak, B. (1998). Inner-ages of middle-aged prime-lifers. The International Journal of Aging \& Human Development, 46, 189-228. http://dx .doi.org/10.2190/Q9X5-8R56-EU39-BEND

Barak, B. (2009). Age identity: A cross-cultural global approach. International Journal of Behavioral Development, 33, 2-11. http://dx.doi.org/ 10.1177/0165025408099485

Barak, B., \& Stern, B. (1986). Subjective age correlates: A research note. The Gerontologist, 26, 571-578. http://dx.doi.org/10.1093/geront/26.5 .571

Barnes-Farrell, J. L., \& Piotrowski, M. J. (1989). Workers' perceptions of discrepancies between chronological age and personal age: You're only as old as you feel. Psychology and Aging, 4, 376-377. http://dx.doi.org/ 10.1037/0882-7974.4.3.376

Barnes-Farrell, J. L., \& Piotrowski, M. J. (1991). Discrepancies between chronological age and personal age as a reflection of unrelieved worker stress. Work \& Stress, 5, 177-187. http://dx.doi.org/10.1080/ 02678379108257016

Barrett, A. E. (2003). Socioeconomic status and age identity: The role of dimensions of health in the subjective construction of age. The Journals of Gerontology Series B, Psychological Sciences and Social Sciences, 58, S101-S109. http://dx.doi.org/10.1093/geronb/58.2.S101

Baum, S. K., \& Boxley, R. L. (1983). Age identification in the elderly: Some theoretical considerations. The Gerontologist, 18, 25-30. http:// dx.doi.org/10.2190/NQUW-J6RJ-8RPC-3B1L

Bentler, P. M. (2007). On tests and indices for evaluating structural models. Personality and Individual Differences, 42, 825-829. http://dx.doi.org/ 10.1016/j.paid.2006.09.024

Bliese, P. D. (2000). Within group agreement, non-independence, and reliability. In K. J. Klein \& S. W. Kozlowski (Eds.), Multilevel theory, research, and methods in organizations (pp. 349-381). San Francisco, CA: Jossey-Bass.

Boehm, S., Kunze, F., \& Bruch, H. (2014). Spotlight on age-diversity climate: The impact of age-related HR practices on firm-level outcomes. Personnel Psychology, 67, 667-704.

Browne, M., \& Cudeck, R. (1993). Alternate ways of assessing model fit. In K. A. Bollen \& J. S. Long (Eds.), Testing structural equation models (pp. 136-162). Newbury Park, CA: Sage.

Carstensen, L. L., Isaacowitz, D. M., \& Charles, S. T. (1999). Taking time seriously: A theory of socioemotional selectivity. American Psychologist, 54, 165-181. http://dx.doi.org/10.1037/0003-066X.54.3.165

Catterall, M., \& Maclaran, P. (2001). Body talk: Questioning the assumptions in cognitive age. Psychology \& Marketing, 18, 1117-1133. http:// dx.doi.org/10.1002/mar.1046

Caudroit, J., Stephan, Y., Chalabaev, A., \& Le Scanff, C. (2012). Subjective age and social-cognitive determinants of physical activity in active older adults. Journal of Aging and Physical Activity, 20, 484-496. 
Chan, D. (1998). Functional relations among constructs in the same content domain at different levels of analysis: A typology of composition models. Journal of Applied Psychology, 83, 234-246. http://dx.doi.org/ 10.1037/0021-9010.83.2.234

Chen, G., Gully, S. M., \& Eden, D. (2001). Validation of a New General Self-Efficacy Scale. Organizational Research Methods, 4, 62-83. http:// dx.doi.org/10.1177/109442810141004

Choi, S., \& Rainey, H. G. (2010). Managing diversity in U.S. Federal agencies: Effects of diversity and diversity management on employee perceptions of organizational performance. Public Administration Review, 70, 109-121. http://dx.doi.org/10.1111/j.1540-6210.2009.02115.x

Choi, Y. R., \& Shepherd, D. A. (2005). Stakeholder perceptions of age and other dimensions of newness. Journal of Management, 31, 573-596. http://dx.doi.org/10.1177/0149206304272294

Delaney, J. T., \& Huselid, M. A. (1996). The impact of human resource management practices on perceptions of organizational performance. Academy of Management Journal, 39, 949-969. http://dx.doi.org/ $10.2307 / 256718$

Dess, G. G., \& Robinson, R. B. (1984). Measuring organizational performance in the absence of objective measures: The case of the privately held firm and conglomerate business unit. Strategic Management Journal, 5, 265-273. http://dx.doi.org/10.1002/smj.4250050306

Dickson, M. W., Resick, C. J., \& Hanges, P. J. (2006). Systematic variation in organizationally-shared cognitive prototypes of effective leadership based on organizational form. The Leadership Quarterly, 17, 487-505. http://dx.doi.org/10.1016/j.leaqua.2006.07.005

Dutton, J. E., Dukerich, J. M., \& Harquail, C. V. (1994). Organizational images and member identification. Administrative Science Quarterly, 39, 239-263. http://dx.doi.org/10.2307/2393235

Ebner, N. C., Freund, A. M., \& Baltes, P. B. (2006). Developmental changes in personal goal orientation from young to late adulthood: From striving for gains to maintenance and prevention of losses. Psychology and Aging, 21, 664-678. http://dx.doi.org/10.1037/0882-7974.21.4.664

Galambos, N. L., Turner, P. K., \& Tilton-Weaver, L. C. (2005). Chronological and subjective age in emerging adulthood: The Crossover Effect. Journal of Adolescent Research, 20, 538-556. http://dx.doi.org/10.1177/ 0743558405274876

Garcia Marquez, G. (2007). Memories of my melancholy whores. New York, NY: Penguin.

Gielnik, M. M., Zacher, H., \& Frese, M. (2012). Focus on opportunities as a mediator of the relationship between business owners' age and venture growth. Journal of Business Venturing, 27, 127-142. http://dx.doi.org/ 10.1016/j.jbusvent.2010.05.002

Gratton, L., Voigt, A., \& Erickson, T. (2007). Bridging faultlines in diverse teams. Sloan Management Review, 48, 22-29.

Greenberg, J., Ashton-James, C. E., \& Ashkanasy, N. M. (2007). Social comparison processes in organizations. Organizational Behavior and Human Decision Processes, 102, 22-41. http://dx.doi.org/10.1016/j .obhdp.2006.09.006

Guiot, D. (2001). Antecedents of subjective age biases among senior women. Psychology \& Marketing, 18, 1049-1071. http://dx.doi.org/ 10.1002/mar.1043

Heckhausen, J., Wrosch, C., \& Schulz, R. (2010). A motivational theory of life-span development. Psychological Review, 117, 32-60. http://dx.doi .org/10.1037/a0017668

Holbeche, L., \& Springett, N. (2004). In search of meaning at work. Horsham, PA: Roffey Park Institute.

Homer, J. L., \& Griffin, A. B. (2006). Bridging the skills gap: How the skills shortage threatens growth and competitiveness. . and what to do about it. Alexandria, VA: ASTD.

Hu, L., \& Bentler, P. M. (1999). Cutoff criteria for fit indexes in covariance structure analysis: Conventional criteria versus new alternatives. Structural Equation Modeling, 6, 1-55. http://dx.doi.org/10.1080/ 10705519909540118
Hubley, A. M., \& Russell, L. B. (2009). Prediction of subjective age, desired age, and age satisfaction in older adults: Do some health dimensions contribute more than others? International Journal of Behavioral Development, 33, 12-21. http://dx.doi.org/10.1177/0165025408099486

Huselid, M. A. (1995). The impact of human resource management practices on turnover, productivity, and corporate financial performance. Academy of Management Journal, 38, 635-672. http://dx.doi.org/ $10.2307 / 256741$

Ilmakunnas, P., \& Ilmakunnas, S. (2011). Diversity at the workplace: Whom does it benefit? De Economist, 159, 1-33. http://dx.doi.org/ 10.1007/s10645-011-9161-X

James, L. R., Demaree, R. G., \& Wolf, G. (1984). Estimating within-group interrater reliability with and without response bias. Journal of Applied Psychology, 69, 85-98. http://dx.doi.org/10.1037/0021-9010.69.1.85

Jansen, J. J., Van Den Bosch, F. A., \& Volberda, H. W. (2006). Exploratory innovation, exploitative innovation, and performance: Effects of organizational antecedents and environmental moderators. Management Science, 52, 1661-1674. http://dx.doi.org/10.1287/mnsc.1060.0576

Kastenbaum, R., Derbin, V., Sabatini, P., \& Artt, S. (1972). "The ages of me": Toward personal and interpersonal definitions of functional aging. International Journal of Aging \& Human Development, 3, 197-211. http://dx.doi.org/10.2190/TUJR-WTXK-866Q-8QU7

Kooij, D. T., de Lange, A. H., Jansen, P. G., \& Dikkers, J. S. (2013). Beyond chronological age. Examining perceived future time and subjective health as age-related mediators in relation to work-related motivations and well-being. Work \& Stress, 27, 88-105. http://dx.doi.org/ 10.1080/02678373.2013.769328

Kooij, D. T., De Lange, A. H., Jansen, P. G., Kanfer, R., \& Dikkers, J. S. (2011). Age and work related motives: Results of a meta-analysis. Journal of Organizational Behavior, 32, 197-225. http://dx.doi.org/ 10.1002/job.665

Kunze, F., Boehm, S., \& Bruch, H. (2011). Age diversity, age discrimination, and performance consequences- a cross organizational study. Journal of Organizational Behavior, 32, 264-290. http://dx.doi.org/ 10.1002/job.698

Kunze, F., Boehm, S., \& Bruch, H. (2013). Organizational performance consequences of age diversity: Inspecting the role of diversity-friendly HR policies and top managers' negative age stereotypes. Journal of Management Studies, 50, 413-442. http://dx.doi.org/10.1111/joms 12016

Lang, F. R., \& Carstensen, L. L. (2002). Time counts: Future time perspective, goals, and social relationships. Psychology and Aging, 17, 125-139. http://dx.doi.org/10.1037/0882-7974.17.1.125

Lawrence, B. S. (1988). New wrinkles in the theory of age: Demography, norms, and performance ratings. Academy of Management Journal, 31, 309-337. http://dx.doi.org/10.2307/256550

Lawrence, B. S. (2004). How old you are may depend on where you work. In D. Chowdhury (Ed.), Next generation business handbook: New strategies from tomorrow's thought leaders (pp. 986-1006). Hoboken, NJ: Wiley. http://dx.doi.org/10.1002/9780470172223.ch57

Maitlis, S., \& Christianson, M. (2014). Sensemaking in organizations: Taking stock and moving forward. The Academy of Management Annals, 8, 57-125. http://dx.doi.org/10.1080/19416520.2014.873177

Montepare, J. M. (2009). Subjective age: Toward a guiding lifespan framework. International Journal of Behavioral Development, 33, 4246. http://dx.doi.org/10.1177/0165025408095551

Ng, T. W. H., \& Feldman, D. C. (2008). The relationship of age to ten dimensions of job performance. Journal of Applied Psychology, 93, 392-423. http://dx.doi.org/10.1037/0021-9010.93.2.392

Ng, T. W., \& Feldman, D. C. (2010). The relationship of age with job attitudes: A meta-analysis. Personnel Psychology, 63, 677-718. http:// dx.doi.org/10.1111/j.1744-6570.2010.01184.x 
Ng, T. W., \& Feldman, D. C. (2012). Evaluating six common stereotypes about older workers with meta-analytical data. Personnel Psychology, 65, 821-858. http://dx.doi.org/10.1111/peps. 12003

Parker, S. K. (1998). Enhancing role breadth self-efficacy: The roles of job enrichment and other organizational interventions. Journal of Applied Psychology, 83, 835-852. http://dx.doi.org/10.1037/0021-9010.83.6 .835

Peeters, M., \& Groot, L. (2012). Demographic change across the globemaintaining social security in ageing economies. World Economy, 13, 75-97.

Pfeffer, J., \& Fong, C. T. (2005). Building organization theory from first principles: The self-enhancement motive and understanding power and influence. Organization Science, 16, 372-388. http://dx.doi.org/ 10.1287/orsc. 1050.0132

Podsakoff, P. M., MacKenzie, S. B., \& Podsakoff, N. P. (2012). Sources of method bias in social science research and recommendations on how to control it. Annual Review of Psychology, 63, 539-569. http://dx.doi.org/ 10.1146/annurev-psych-120710-100452

Posthuma, R. A., \& Campion, M. A. (2009). Age stereotypes in the workplace: Common stereotypes, moderators, and future research directions. Journal of Management, 35, 158-188. http://dx.doi.org/10.1177/ 0149206308318617

Preacher, K. J., Rucker, D. D., \& Hayes, A. F. (2007). Addressing moderated mediation hypotheses: Theory, methods, and prescriptions. Multivariate Behavioral Research, 42, 185-227. http://dx.doi.org/10.1080/ 00273170701341316

Pulakos, E. D., Arad, S., Donovan, M. A., \& Plamondon, K. E. (2000). Adaptability in the workplace: Development of a taxonomy of adaptive performance. Journal of Applied Psychology, 85, 612-624. http://dx.doi .org/10.1037/0021-9010.85.4.612

Pulakos, E. D., Dorsey, D. W., \& White, S. S. (2006). Adaptability in the workplace: Selecting an adaptive workforce. In C. S. Burk, L. G. Pierce, \& E. Salas (Eds.), The Oxford handbook of work and aging (pp. 41-71). New York, NY: Oxford University Press. http://dx.doi.org/10.1016/ S1479-3601(05)06002-9

Quinones, M. A., Ford, J. K., \& Teachout, M. A. (1995). The relationship between work experience and job performance: A conceptual and metaanalytic review. Personnel Psychology, 48, 887-910. http://dx.doi.org/ 10.1111/j.1744-6570.1995.tb01785.x

Raes, A. M. L., Bruch, H., \& De Jong, S. B. (2013). How top management team behavioral integration can impact employee work outcomes: Theory development and first empirical tests. Human Relations, 66, 167192. http://dx.doi.org/10.1177/0018726712454554

Ragins, B. R., Cotton, J. L., \& Miller, J. S. (2000). Marginal mentoring: The effects of type of mentor, quality of relationship, and program design on work and career attitudes. Academy of Management Journal, 43, 1177-1194. http://dx.doi.org/10.2307/1556344

Rogers, E. W., \& Wright, P. M. (1998). Measuring organizational performance in strategic human resource management: Problems, prospects and performance information markets. Human Resource Management Review, 8, 311-331. http://dx.doi.org/10.1016/S1053-4822(98)90007-9

Rosen, B., \& Jerdee, T. H. (1976). The influence of age stereotypes on managerial decisions. Journal of Applied Psychology, 61, 428-432. http://dx.doi.org/10.1037/0021-9010.61.4.428

Rubin, D. C., \& Berntsen, D. (2006). People over forty feel $20 \%$ younger than their age: Subjective age across the lifespan. Psychonomic Bulletin \& Review, 13, 776-780. http://dx.doi.org/10.3758/BF03193996

Schneider, B. (1987). The people make the place. Personnel Psychology, 40, 437-453. http://dx.doi.org/10.1111/j.1744-6570.1987.tb00609.x
Schwall, A. R. (2012). Defining age and using age-relevant constructs. In J. W. Hedge \& W. C. Borman (Eds.), The Oxford handbook of work and aging (pp. 169-186). New York, NY: Oxford University Press.

Smircich, L., \& Morgan, G. (1982). Leadership: The management of meaning. Journal of Applied Behavioral Science, 18, 257-273. http://dx doi.org/10.1177/002188638201800303

Spreitzer, G. M. (1995). Psychological empowerment in the workplace: Dimensions, measurement, and validation. Academy of Management Journal, 38, 1442-1465. http://dx.doi.org/10.2307/256865

Starbuck, W. H. (2004). Methodological challenges posed by measures of performance. Journal of Management and Governance, 8, 337-343. http://dx.doi.org/10.1007/s10997-004-4125-Z

Stephan, Y., Chalabaev, A., Kotter-Grühn, D., \& Jaconelli, A. (2013). "Feeling younger, being stronger": An experimental study of subjective age and physical functioning among older adults. The Journals of Gerontology Series B, Psychological Sciences and Social Sciences, 68, 1-7. http://dx.doi.org/10.1093/geronb/gbs037

Stephan, Y., Demulier, V., \& Terracciano, A. (2012). Personality, selfrated health, and subjective age in a life-span sample: The moderating role of chronological age. Psychology and Aging, 27, 875-880. http:// dx.doi.org/10.1037/a0028301

Stock, J. H., Wright, J. H., \& Yogo, M. (2002). A survey of weak instruments and weak identification in generalized method of moments. Journal of Business \& Economic Statistics, 20, 518-529. http://dx.doi .org/10.1198/073500102288618658

Taylor, A. B., MacKinnon, D. P., \& Tein, J. Y. (2008). Tests of the three-path mediated effect. Organizational Research Methods, 11, 241269. http://dx.doi.org/10.1177/1094428107300344

Teuscher, U. (2009). Subjective age bias: A motivational and information processing approach. International Journal of Behavioral Development, 33, 22-31. http://dx.doi.org/10.1177/0165025408099487

Thomas, K. W., \& Velthouse, B. A. (1990). Cognitive elements of empowerment: An "interpretive" model of intrinsic task motivation. The Academy of Management Review, 15, 666-681.

Toossi, M. (2012). Labor force projections to 2020: A more slowly growing workforce. Monthly Labor Review, 135, 34-64.

Wall, T. D., Michie, J., Patterson, M., Wood, S. J., Sheehan, M., Clegg, C. W., \& West, M. (2004). On the validity of subjective measures of company performance. Personnel Psychology, 57, 95-118. http://dx.doi .org/10.1111/j.1744-6570.2004.tb02485.x

Westerhof, G. J., Barrett, A. E., \& Steverink, N. (2003). Forever young? A comparison of age identities in the United States and Germany. Research on Aging, 25, 366-383. http://dx.doi.org/10.1177/ 0164027503025004002

Yukl, G. (2008). How leaders influence organizational effectiveness. The Leadership Quarterly, 19, 708-722. http://dx.doi.org/10.1016/j.leaqua .2008.09.008

Zacher, H., \& Frese, M. (2009). Remaining time and opportunities at work: Relationships between age, work characteristics, and occupational future time perspective. Psychology and Aging, 24, 487-493. http://dx.doi.org/ 10.1037/a0015425

Zacher, H., \& Frese, M. (2011). Maintaining a focus on opportunities at work: The interplay between age, job complexity, and the use of selection, optimization, and compensation strategies. Journal of Organizational Behavior, 32, 291-318. http://dx.doi.org/10.1002/job.683 